\title{
Valorization of incinerator bottom ash for the production of resource-efficient eco-friendly concrete: Performance and toxicological characterization
}

\author{
B. M. Ramesh ${ }^{1} \cdot$ Rahul Murali Vongole $^{1} \cdot{\text { Yashas } \text { Nagraj }^{1} \cdot \text { Sujay Raghavendra Naganna }^{2} \text { (D) B. M. Sreedhara }}^{2}$. \\ Gireesh Mailar $^{3}$. P. S. Ramesh ${ }^{4}$. Zaher Mundher Yaseen ${ }^{5}$
}

Received: 29 April 2021 / Accepted: 20 August 2021 / Published online: 18 September 2021

(C) The Author(s), under exclusive licence to Springer Nature Switzerland AG 2021

\begin{abstract}
In recent times, the quantity of wastes generated from industries, hospitals, construction sites etc. is perpetually increasing from year to year. Producing concrete utilizing waste or discarded materials as a partial replacement to fine or coarse aggregates is one among the effective ways of waste utilization. The disposal of incinerator bottom ash usually produced by the incineration of inorganic constituents of the municipal solid wastes (MSW) in an eco-friendly way is one of the issues of concern, globally. By the way, the present study is related to the utilization of MSW incinerator bottom ash and recycled demolition waste aggregate as partial replacement materials for fine and coarse aggregate, respectively to produce eco-friendly concrete. This study adopted an innovative pretreatment technique for stabilizing the MSW incinerator bottom ash. Five distinct M20 grade concrete mixes were produced with different proportions of fine aggregate, MSW incinerator bottom ash, coarse aggregate, and recycled demolition waste aggregate along with cement and water. The incinerator bottom ash was replaced at 5\% and 10\% quantities with fine aggregate and the recycled demolition waste aggregate was replaced at $40 \%$ and $60 \%$ of the weight of the coarse aggregate. The strength and durability properties of the M20 grade concrete were analyzed. It was noticed that the strength and durability properties of the eco-friendly concrete specimens produced by incorporating 5\% - incinerator bottom ash and 40\% - recycled demolition waste aggregate were superior to that of the control mix concrete. Laboratory tank leaching tests showed that the eco-friendly concrete do not pose any significant environmental hazard. Furthermore, the microstructural analysis through scanning electron microscope (SEM) images, revealed dense aggregate paste matrix interfaces with less micro-pores and insignificant micro-cracks due to the incorporation of incinerator bottom ash as a partial replacement to the fine aggregate.
\end{abstract}

Keywords Eco-friendly concrete $\cdot$ Incinerator bottom ash $\cdot$ Recycled demolition waste $\cdot$ Durability $\cdot$ Toxicity analysis

Sujay Raghavendra Naganna sujay.gopan@gmail.com

1 Department of Civil Engineering, SJB Institute of Technology, Kengeri, Bengaluru - 560060, India

2 Department of Civil Engineering, Siddaganga Institute of Technology, Tumakuru - 572103, India

3 Department of Civil Engineering, Rural Engineering College, Hulkoti - 582205, Gadag, India

4 Department of Civil Engineering, Nagarjuna College of Engineering and Technology, Devanahalli, Bengaluru - 562110, India

5 New Era and Development in Civil Engineering Research Group, Scientific Research Center, Al-Ayen University, Thi-Qar, Nasiriyah, 64001, Iraq

\section{Introduction}

Eco-friendly Concrete is a latest terminology given to the variety of concrete produced by incorporating waste/discarded and recycled materials [1, 2]. Globally, several researchers have manufactured eco-friendly concrete using a wide-range of waste, recycled and composite materials [3-6]. The benefit of eco-friendly concrete is twofold: firstly its strength and durability properties are consistent with that of the conventional concrete, even though it includes discarded and recycled materials and secondly it contributes for waste minimization and management in a eco-friendly way [4]. Some of the waste or discarded materials partially replaced with cement are fly ash, silica fume, ground granulated blast-furnace slag, rice husk ash etc. Similarly, the fine aggregates are partially replaced with wastes 
such as spent foundry sand, coal combustion residues, bagasse ash, peanut shell ash, marble dust, waste gypsum, copper tailing, zinc tailing, lime sludge, powdered ceramic waste, waste incineration ash, saw dust, powdered oyster shells etc., and coarse aggregates are partially replaced with discarded materials such as building demolition waste, waste glass pieces, rubber/tyre latex, crushed waste tiles, reclaimed asphalt, waste plastic chops etc. [7].

The International Solid Waste Association (ISWA), ranked India in the $3^{\text {rd }}$ position among several countries of the world in the production of waste, particularly the municipal solid waste (MSW), with about 1.1 kilo tons of waste generated per day [8]. However, when it comes to recycling, the quantity of waste that enters into the recycling loop is very minimal and most of the wastes end up either in landfills or combustion plants. The inorganic waste materials that find way into the combustion plants in turn exit as incinerator bottom ash along with the release of toxic fumes into the air [9]. Its imprudent to bury such incinerator ash in a conventional municipal landfill [10]. The proper management or disposal of this incinerator bottom ash is always one of the challenging issue because it requires an advanced hazard mitigating landfill which is much costlier than the conventional one [11]. Several studies in the literature report, utilizing the incinerator ash as a substitute to fine aggregate in mass concreting works is an eco-friendly option for effective management of incinerator bottom ash [12-14].

The ever increasing urban expansion in cities has led to generation of construction and demolition $(C \& D)$ waste due to the renovation and demolition of existing structures or housing units. The demolished concrete blocks, brick masonry units, timber, metals, glass, ceramics, flooring mosaics and rubble constitute a bulk of $\mathrm{C} \& \mathrm{D}$ wastes $[15$,

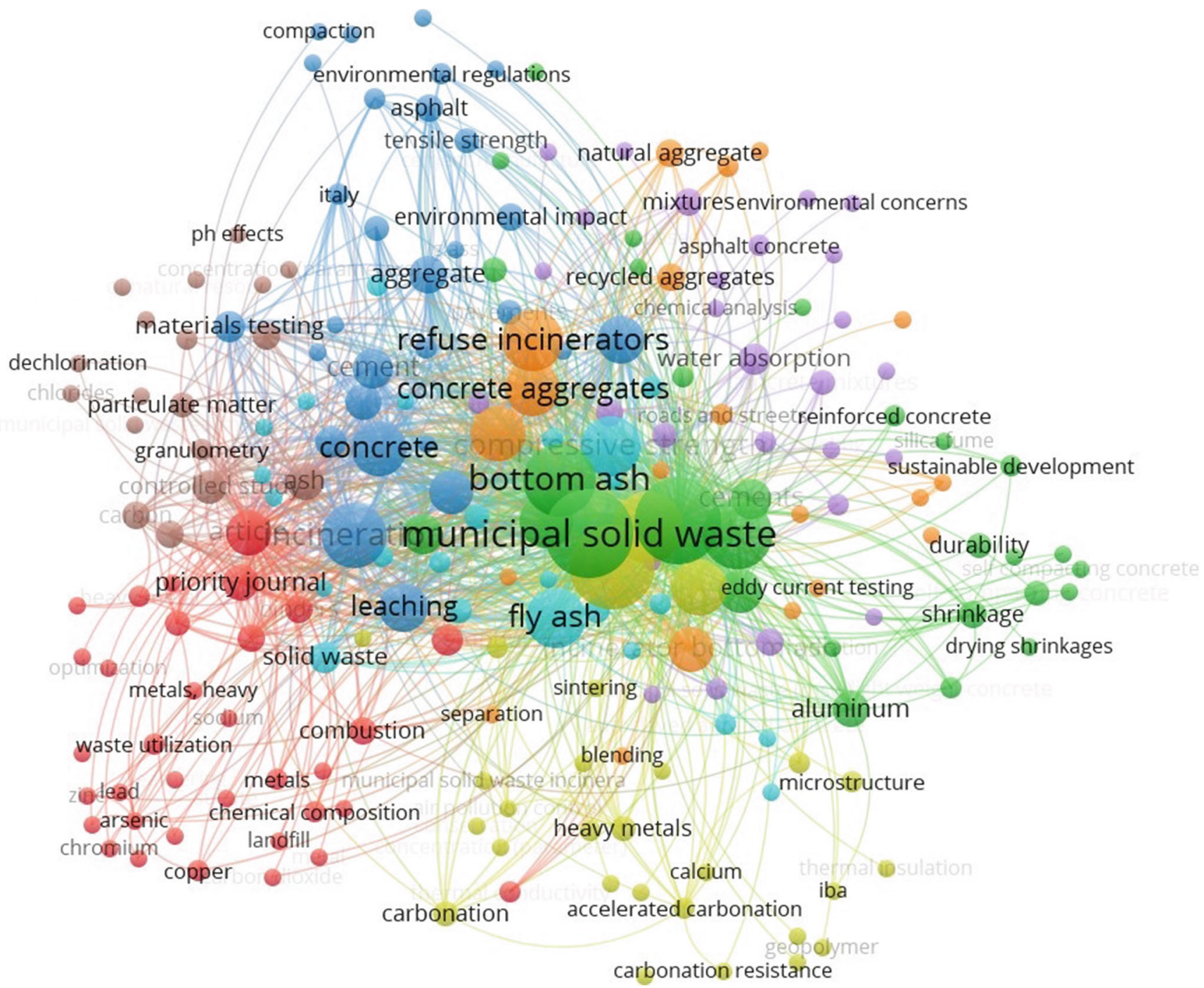

Fig. 1 VOSviewer visualization of the major keywords related to literature on using MSW incinerator bottom ash as a component of concrete. The inter-relations between terms are shown as well 
16]. Currently, in India, 10-12 million tons of C\&D waste is generated annually and a larger part of these squanders are finding their way into low lying areas, tank/pond bunds, illegal dumping into stream/river course and some into landfill sites [17]. Mass awareness, best management practices and a stringent government authority to monitor and utilize huge quantities of $C \& D$ waste is a need of the hour in India.

Over the time, several studies conducted on the usage of the incinerator bottom ash as a partial replacement to fine aggregate [18-22] and recycled coarse aggregate (RCA) from building demolition waste as partial or complete replacement to coarse aggregate [23, 24]. Zhang and Zhao (2014) [25] in their investigation witnessed low chemical reactivity between the MSW incinerator bottom ash and cement in addition to an increase in the setting time (both initial and final) of the cement paste containing ash in it. In a study by Al Muhit et al. (2015) [18], the concrete incorporating MSW incinerator ash didn't gain enhanced strength and durability properties yet, held analogous properties as that of control mix samples. Some researchers who witnessed harmful components in the MSW incinerator bottom ash developed pretreatment methods for eliminating the adverse effects of reactive compounds present in the ash and thereafter managed it as a partial replacement material in concrete $[26,27]$. Zhu et al. (2016) [28] conducted field emission scanning electron microscopy (FESEM) tests to examine the heterogeneity in components of MSW incinerator bottom ash mass. Intrinsic microstructural non-uniformity was noticed in cement mortar due to the ash impurities embedded in the mortar that created cavities, micro pores and nano-cracks in the matrix hindering the adhesion of fine particles to the aggregates. The MSW incinerator bottom ash exhibited higher porosity and absorption properties in a study by Lynn et al. (2016) [26]. The mortar produced by considering MSW incinerator bottom ash as a fine aggregate had reduced elastic modulus, compressive and flexural strengths when compared to that of natural aggregate mixes due to organic fraction in the ash. Liu et al. (2018) [29] developed an alkali treatment method for the removal of metallic aluminum from MSW incinerator bottom ash which indeed enhanced the pozzolanic properties of ash. $\mathrm{Li}$ et al. (2018) [30] found that with the substitution of quartz sand with MSW incinerator bottom ash by about $60 \%$ in autoclaved aerated concrete, the compressive strength and bulk density of concrete met the requirements of Chinese national standard. Even though recycled coarse aggregate concrete is advantageous in terms of economy and reduction in the use of natural (virgin) aggregates, some of the

Table 1 Physical and Chemical Properties of 53 Grade OPC Cement

\begin{tabular}{|c|c|c|}
\hline Properties & OPC 53 Grade & IS Requirement \\
\hline \multicolumn{3}{|l|}{ Physical properties } \\
\hline Specific surface $\left(\mathrm{m}^{2} / \mathrm{kg}\right)$ & 280 & $225 \mathrm{~min}$ \\
\hline \multicolumn{3}{|l|}{ Setting Time (minutes) } \\
\hline Initial & 70 & $30 \mathrm{~min}$. \\
\hline Final & 250 & $600 \max$. \\
\hline \multicolumn{3}{|l|}{ Soundness } \\
\hline By Le-Chatelier (mm) & 3 & 10 max. \\
\hline By Autoclave (\%) & 0.2 & $0.8 \max$ \\
\hline \multicolumn{3}{|l|}{ Compressive strength (MPa) } \\
\hline 3 days & 35 & $27 \mathrm{~min}$. \\
\hline 7 days & 45 & 37 min. \\
\hline 28 days & 58 & $53 \mathrm{~min}$. \\
\hline \multicolumn{3}{|l|}{ Chemical Composition } \\
\hline Chloride $(\mathrm{Cl})(\%)$ & $0.05 \max$. & $0.10 \max$ \\
\hline Magnesium oxide (MgO) (\%) & $2.5 \max$ & $6.0 \max$. \\
\hline Sulphuric anhydride $\left(\mathrm{SO}_{3}\right)(\%)$ & 2.75 max. & $\begin{array}{l}2.5 \text { max. when } \mathrm{C} 3 \mathrm{~A}<5 \\
3.0 \text { max. when } \mathrm{C} 3 \mathrm{~A}>5\end{array}$ \\
\hline Alumina Iron Ratio (A/F) (\%) & $1.10 \mathrm{~min}$. & $0.66 \mathrm{~min}$ \\
\hline Lime Saturation Factor (LSF) (\%) & $0.90 \mathrm{~min}$. & $0.80-1.02$ \\
\hline Insoluble residues $(\%)$ & 2.0 max. & $3.0 \max$ \\
\hline Loss of Ignition (\%) & $3.0 \max$. & $4.0 \max$. \\
\hline
\end{tabular}

min. - minimum; max. - maximum 
Table 2 Physical Properties of Coarse and Fine Aggregates

\begin{tabular}{llll}
\hline Property & Fine Aggregate & Coarse Aggregate & Crushed Granite Gravel \\
\cline { 2 - 4 } & M sand & Recycled Demolition Waste & $20 \mathrm{~mm}$ and down \\
\hline Particle size & $4.75 \mathrm{~mm}$ and down & $20 \mathrm{~mm}$ and down & 6.35 \\
Fineness modulus & 2.73 & 6.19 & 2.74 \\
Specific gravity & 2.59 & 2.70 & $0.33 \%$ \\
Water Absorption & $0.55 \%$ & $0.45 \%$ & $1545 \mathrm{~kg} / \mathrm{m}^{3}$ \\
Bulk Density & $1510 \mathrm{~kg} / \mathrm{m}^{3}$ & $1504 \mathrm{~kg} / \mathrm{m}^{3}$ & \\
\hline
\end{tabular}

disadvantages include increase in water absorption capacity of concrete along with reduction in compressive strength and workability of the concrete [31-33].

It is worth to visualize the reported literature on the usage of MSW incinerator bottom ash in concrete. Over 50 articles were observed in the Scopus database and the major related keywords are displayed using VOSviewer cluster algorithm as shown in Figure 1. This research topic is too broad focused and different engineering aspects are explored and investigated. Among different countries, India presented

Table 3 Physico-chemical properties of treated MSW Incineration bottom ash

\begin{tabular}{|c|c|c|c|c|}
\hline Property & $\begin{array}{l}\text { Number of } \\
\text { samples }\end{array}$ & Mean & $\begin{array}{l}\text { Standard } \\
\text { Deviation }\end{array}$ & Range \\
\hline \multicolumn{5}{|l|}{ Physical Properties } \\
\hline Specific Gravity & 6 & 1.96 & 0.13 & $1.78-2.16$ \\
\hline Bulk Density $\left(\mathrm{kg} / \mathrm{m}^{3}\right)$ & 6 & 1186.67 & 126.32 & $985-1330$ \\
\hline Water Absorption (\%) & 6 & 12.48 & 0.48 & $11.8-13.20$ \\
\hline \multicolumn{5}{|c|}{$\rightarrow$ Fine Fraction $(<4.75 \mathrm{~mm})$} \\
\hline Fineness modulus & 6 & 1.98 & 0.10 & $1.85-2.10$ \\
\hline \multicolumn{5}{|l|}{ Chemical Composition } \\
\hline $\mathrm{SiO}_{2}(\%)$ & 6 & 23.25 & 4.68 & $18.67-29.26$ \\
\hline $\mathrm{CaO}(\%)$ & 6 & 9.33 & 2.89 & $6.66-13.09$ \\
\hline $\mathrm{Fe}_{2} \mathrm{O}_{3}(\%)$ & 6 & 15.86 & 4.85 & $10.25-21.12$ \\
\hline $\mathrm{Al}_{2} \mathrm{O}_{3}(\%)$ & 6 & 6.65 & 2.34 & $3.76-9.12$ \\
\hline $\mathrm{Na}_{2} \mathrm{O}(\%)$ & 6 & 3.65 & 0.95 & $2.15-4.96$ \\
\hline $\mathrm{SO}_{3}(\%)$ & 6 & 1.06 & 0.32 & $0.22-1.87$ \\
\hline $\mathrm{TiO}_{2}(\%)$ & 6 & 0.89 & 0.18 & Nil - 1.34 \\
\hline $\mathrm{K}_{2} \mathrm{O}(\%)$ & 6 & 1.56 & 0.43 & $0.72-2.43$ \\
\hline $\mathrm{MgO}(\%)$ & 6 & 3.28 & 0.95 & $1.68-4.64$ \\
\hline $\mathrm{P}_{2} \mathrm{O}_{5}(\%)$ & 6 & 0.76 & 0.23 & Nil - 1.47 \\
\hline $\mathrm{ZnO}(\%)$ & 6 & 4.55 & 1.15 & $2.06-5.98$ \\
\hline $\mathrm{KCl}(\%)$ & 6 & 3.76 & 1.05 & $1.27-5.05$ \\
\hline $\mathrm{PbO}(\%)$ & 6 & 1.68 & 0.56 & $0.45-2.38$ \\
\hline $\mathrm{MnO}_{2}(\%)$ & 6 & 5.89 & 1.28 & $3.08-7.16$ \\
\hline $\mathrm{BaO}(\%)$ & 6 & 0.68 & 0.21 & Nil - 0.94 \\
\hline $\mathrm{Cu}_{2} \mathrm{O}(\%)$ & 6 & 4.28 & 1.45 & $2.11-6.16$ \\
\hline $\mathrm{Cr}_{2} \mathrm{O}_{3}(\%)$ & 6 & 0.75 & 0.30 & Nil - 1.07 \\
\hline $\mathrm{NiO}(\%)$ & 6 & 2.28 & 0.76 & $0.98-4.55$ \\
\hline $\mathrm{V}_{2} \mathrm{O}_{5}(\%)$ & 6 & 0.49 & 0.11 & Nil - 0.87 \\
\hline Residues (\%) & 6 & 4.68 & 2.17 & $2.03-6.97$ \\
\hline LOI $(\%)$ & 6 & 2.87 & 0.77 & $1.95-3.08$ \\
\hline
\end{tabular}

LOI: Loss of Ignition 
minor research in this research domain and the MSW incinerator bottom ash generated in the country is a major concern for its environment. Hence, there is a provision for cautious use of MSW incinerator bottom ash as a fine aggregate in concrete. The physico-chemical properties of incinerator ash vary from one bulk to the other due to the changes or non-uniformity in the waste load shredded to the incinerator from batch to batch [34]. In addition, the MSW incinerator bottom ash is known to include several toxic residues along with heavy metals and varying amounts of moisture due to quenching [35]. Further, the inconsistency in the composition of the incinerator bottom ash makes it an antagonistic material for use in concrete production [36]. Thus, its obligatory to treat and test the physiochemical properties of MSW incinerator bottom ash before employing it as a partial replacement material in concrete production. This is where the current research contribution and motivation are presented.

Based on the chemical composition of MSW incinerator bottom ash, an efficient pretreatment system has to be designed to transform it into a stable, non-reactive (inert) and homogeneous material. Hence, the objective of the present study was to design an innovative pretreatment technique for stabilizing the MSW incinerator bottom ash and thereafter utilize it as a partial replacement material to fine aggregate. The recycled demolition waste aggregate was also employed as a substitution material for coarse aggregate to produce eco-friendly concrete. This study adopted an innovative pretreatment technique for stabilizing the incinerator bottom ash. Five distinct M20 grade concrete mixes as per Indian Standard (IS) codal provisions were designed and produced with different proportions of fine aggregate (M-sand), MSW incinerator bottom ash, coarse aggregate, recycled demolition waste aggregate along with cement and water. A standard/control concrete mix and four other trial concrete mix proportions containing $5 \%$ or
$10 \%$ of MSW incinerator bottom ash, and $40 \%$ or $60 \%$ of recycled demolition waste aggregate were designed. The MSW incinerator bottom ash was restricted just up to $10 \%$ substitution taking into account of the adverse impacts that may happen such as cavities, micro-pores, micro-cracks, and leaching of heavy metals from concrete at higher replacement percentages [28]. Similarly, the recycled demolition waste aggregate was replaced at $40 \%$ and $60 \%$ for the reason that no significant variations were observed in the strength properties of recycled aggregate concrete and the conventional concrete in the study by Robu et al. (2016) [37]. The strength, durability and toxicicity properties of the M20 grade concrete specimens are analyzed and reported.

\section{Materials}

\section{Cement}

Ordinary Portland Cement (OPC) conforming to IS:122692013 (2013) [38] of 53 grade was used throughout the experimental programme. The physical properties and chemical composition of cement as furnished by the manufacturer are presented in Table 1.

\section{Aggregates}

The manufactured sand ( $M$ sand) having particle size distribution conforming to the zone II grading of Table 4 of IS:383-1970 (2002) [39] was used as fine aggregate in the present experimental programme. The shape of $\mathrm{M}$ sand grains ranged from spherical to sub-angular with uniform texture. Usually the shaping machine in crushers deliver rounded/spherical shaped M sand grains free from silt, clay, and elongated or flaky particles. Some physical properties of M sand are tabulated in Table 2. The pre-treated MSW
Fig. 2 Bottom ash heap stored at MSW incineration plant location

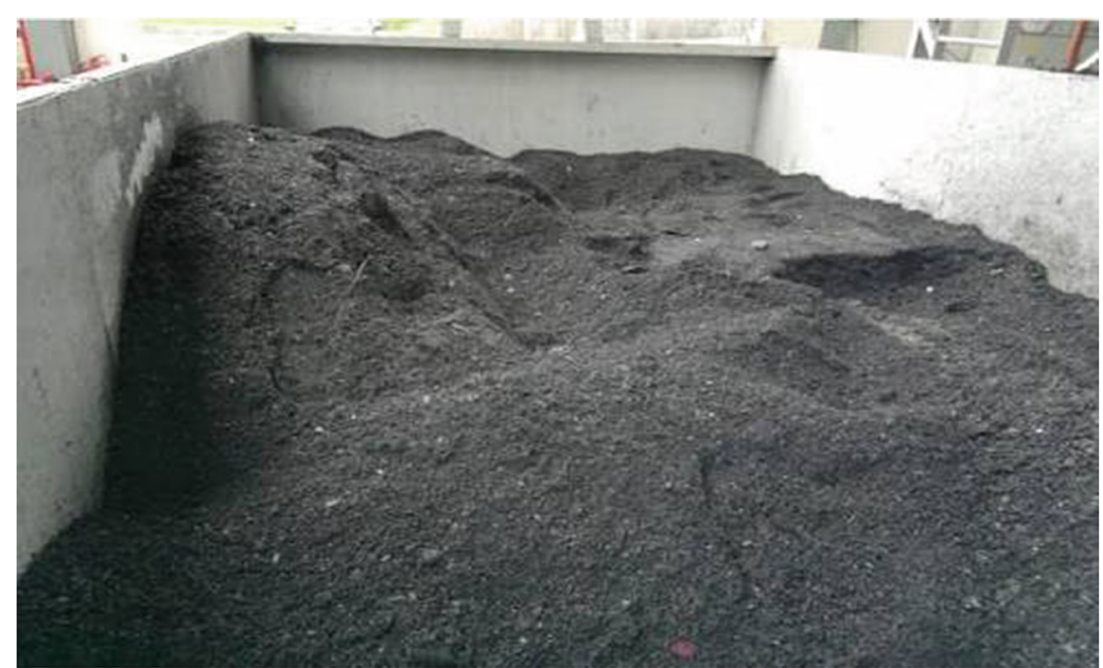


Table 4 Mix composition of concrete mixes

\begin{tabular}{llllll}
\hline MIX & & M1 & M2 & M3 & M4 \\
\hline Cement & Content in $\left(\mathrm{kg} / \mathrm{m}^{3}\right)$ & 425.73 & 425.73 & 425.73 & 425.73 \\
\hline MSW Incinerator & Percentage & 0 & 5 & 5 & 425.73 \\
Bottom ash & Content in $\left(\mathrm{kg} / \mathrm{m}^{3}\right)$ & 0 & 32.25 & 32.25 & 10 \\
M Sand & Percentage & 100 & 95 & 95 & 94.49 \\
& Content in $\left(\mathrm{kg} / \mathrm{m}^{3}\right)$ & 644.94 & 612.69 & 612.69 & 580.45 \\
Crushed Granite & Percentage & 100 & 60 & 40 & 60 \\
Aggregate & Content in $\left(\mathrm{kg} / \mathrm{m}^{3}\right)$ & 1161.73 & 697.04 & 464.69 & 697.04 \\
Recycled Demolition & Percentage & 0 & 40 & 60 & 40 \\
Waste Aggregate & Content in $\left(\mathrm{kg} / \mathrm{m}^{3}\right)$ & 0 & 464.69 & 697.04 & 40 \\
Water to Cement Ratio & Ratio & 0.45 & 0.45 & 0.45 & 464.69 \\
\hline
\end{tabular}

incinerator bottom ash sieved through $4.75 \mathrm{~mm}$ IS sieve was employed as a partial replacement material for $\mathrm{M}$ sand. On the whole, the incinerator bottom ash is a chemically reactive material which need to be stabilized before its use. The stabilization process of MSW incinerator bottom ash is explained in detail in the next section. Meanwhile, the physico-chemical properties of stabilized MSW incinerator bottom ash used in the experimental programme are listed in Table 3.

Crushed granite gravel of $20 \mathrm{~mm}$ downsize were used in addition to recycled demolition waste (RDW) aggregate ${ }^{1}$ as coarse aggregates in the experimental programme of this study. Demolished concrete waste was mechanically crushed to extract the coarse aggregates from it. Visually, the coarse RDW aggregates appeared to be dense and had rough surface for strong bondage with the mortar paste. The properties of crushed granite gravel and RDW aggregates are tabulated in Table 2.

\section{Pretreatment of MSW incinerator bottom ash}

The bottom ash (Figure 2) expelled from MSW incineration plants owned by Gomti Incinco Pvt. Ltd., Bengaluru was used for pretreatment in the current experimental investigations. The MSW incinerator bottom ash so procured was sieved through $4.75 \mathrm{~mm}$ IS sieve with an objective to use it as a partial replacement material for $\mathrm{M}$ sand. The most economic way of preprocessing MSW incinerator bottom ash is through Wet Pretreatment. Listed

\footnotetext{
${ }^{1}$ Mortar waste was discarded/eliminated and only coarse aggregates of demolished concrete were considered for recycling
}

below are steps in the pretreatment procedure implemented to stabilize the MSW incinerator bottom ash.

- About $3 \mathrm{~kg}$ of MSW incinerator bottom ash was processed at once in lab-scale batch experiments. The procedure involves sequential washing with acidic and alkaline solutions followed by cyclic water-washing process until chlorides, sulphates, soluble organic and inorganic residues are evacuated.

- Initially, $1 \mathrm{M} \mathrm{HCl}$ solution of about five times the quantity of ash i.e., 15 liters was taken in a PVC plastic bucket. The MSW incinerator bottom ash was slowly poured into the bucket with constant stirring of $\mathrm{HCl}$ solution and thereafter the mixture was thoroughly stirred at a uniform rate for about 10 minutes. Further, the mixture was allowed to react under stable conditions for another 20 minutes.

- Next, the acid-ash mixture was filtered using a nylon fine mesh filter pad and the filtrate or filter cake was sun dried by uniformly spreading over a PVC sheet.

- Secondly, the acid treated bottom ash was subjected to alkaline treatment by stirring and mixing it with 15 liters of $5 \mathrm{M} \mathrm{NaOH}$ solution. The mixture was again allowed to react under stable conditions for 20 minutes before filtering and later sun dried.

- In the next step, the acid and alkali treated bottom ash was washed using 20 liters of deionized water by mixing and continuously stirring it in a bucket. The mixture was thoroughly stirred at a uniform rate for about 15 minutes and allowed to react under stable conditions for another 10 minutes before filtering. The washed water was tested for the concentration of chlorides and sulphates in it by titration methods. 
Table 5 Results of Slump and Vee-Bee Tests on Fresh Concrete

\begin{tabular}{llll}
\hline MIX & Slump $(\mathrm{mm})$ & Vee-Bee Degrees & Consistency \\
\hline M1 & $74( \pm 3)$ & 4 & Plastic \\
M2 & $84( \pm 3)$ & 3 & Semi-fluid \\
M3 & $80( \pm 3)$ & 3 & Semi-fluid \\
M4 & $90( \pm 3)$ & 2 & Semi-fluid \\
M5 & $87( \pm 3)$ & 3 & Semi-fluid \\
\hline
\end{tabular}

- This water-washing process was carried out until the chlorides and sulphates concentration in the washed water came with in the permissible limits ${ }^{2}$. Finally, the filter cake was sun dried and exposed to open environment for 24 hours and used as a partial replacement material for $\mathrm{M}$ sand.

\section{Experimental programme}

Concrete of M20 Grade was designed as per the guidelines of IS:10262-2009 (2009) [41] with an aim to achieve characteristic compressive strength of $20 \mathrm{MPa}$ at 28 days of curing; however, the design target strength was higher by $33 \%$ of the characteristic compressive strength. The Table 4 unveils the quantity of materials required to produce $1 \mathrm{~m}^{3}$ volume of concrete. The designed concrete mixes were expected to have a slump of $75 \mathrm{~mm}$ for medium degree of workability. Specimens of concrete were cast under mechanical vibration. The control mix (M1) represents the concrete produced without any admixtures/partial replacement materials. Mixes M2 and M3 contained $40 \%$ and $60 \%$ replacement of crushed granite aggregate with RDW aggregate, respectively, in addition to $5 \%$ replacement of $\mathrm{M}$ sand with MSW incinerator bottom ash. Similarly, mixes M4 and M5 were designed to have $10 \%$ replacement of $\mathrm{M}$ sand with $\mathrm{MSW}$ incinerator bottom ash besides $40 \%$ and $60 \%$ replacement of crushed granite aggregate with RDW aggregate, respectively. Influence of MSW incinerator bottom ash and RDW aggregates on the mechanical and durability properties of concrete was studied through laboratory experiments. The concrete mixes M2, M3, M4 and M5 are hereby referred to as eco-friendly concrete.

\section{Determination of fresh and hardened properties of eco-friendly concrete}

Workability and Consistency of concrete mixes with and without partial replacement materials were examined by

\footnotetext{
${ }^{2}$ The permissible limits of chloride and sulphate levels were $<250$ $\mathrm{mg} / \mathrm{l}$ and $200 \mathrm{mg} / \mathrm{l}$, respectively as per IS 10500: 2012[40]
}

conducting Slump \& Vee-Bee consistometer tests as per the guidelines of IS:1199-1959 (1991) [42]. The unconfined compressive strength test was carried out on concrete cubes of size $150 \mathrm{~mm}$ at the age of 3, 7, 14, 28 and 90 days at a standard loading rate as per IS:516-1959 (2006) [43]. Cylindrical specimens of $150 \mathrm{~mm}$ diameter and $300 \mathrm{~mm}$ height were cast for determining the split tensile strength of eco-friendly concrete mixes at the age of 28 days as per IS:5816-1999 220 (2004) [44]. Concrete cast into rectangular prisms (beams) of size $100 \times 100 \times$ $500 \mathrm{~mm}$ and cured in water for 28 days were tested for determining the flexural strength of hardened ecofriendly concrete mixes as per IS:516-1959 (2006) [43] by subjecting each specimen under a two-point loading system where the load is applied at a constant rate perpendicular to the finishing surface of the specimen. Additionally, nondestructive testing (NDT) techniques, namely the Ultrasonic Pulse Velocity (UPV) and Rebound Hammer (RH) tests were conducted as per the guidelines of IS:13311[Part-1]1992 (2004) [45] and IS:13311[Part-2]-1992 (2004) [46], respectively. The strength of concrete cube of each mix was assessed qualitatively by conducting rebound hammer tests at multiple loci of the cube (six readings of rebound number was taken from each face of cube) to arrive at average rebound number.

\section{Determination of durability properties of eco-friendly concrete}

The durability of concrete is a direct function of its porosity and hence the Volume of Permeable Voids (VPV) test was conducted on eco-friendly concrete specimens as per the ASTM:C642-06 (2006) [47] guidelines to assess the quantum of permeable pore space in the hardened eco-friendly concrete specimens. Tank leaching tests were performed to assess the leaching of possibly hazardous substances from the monolithic eco-friendly concrete cylinders in accordance with EA NEN 7375:2004 (2005) [48] protocol. Trace to bulk heavy metals in the leachate samples were analyzed along with other inorganic elements (aluminium, arsenic, barium, boron, cadmium, chromium, cobalt, copper, gallium, iron, lead, manganese, nickel, silver and zinc), using high-performance inductively coupled 
Fig. 3 Compressive strength gain of the eco-friendly concrete mixes with age

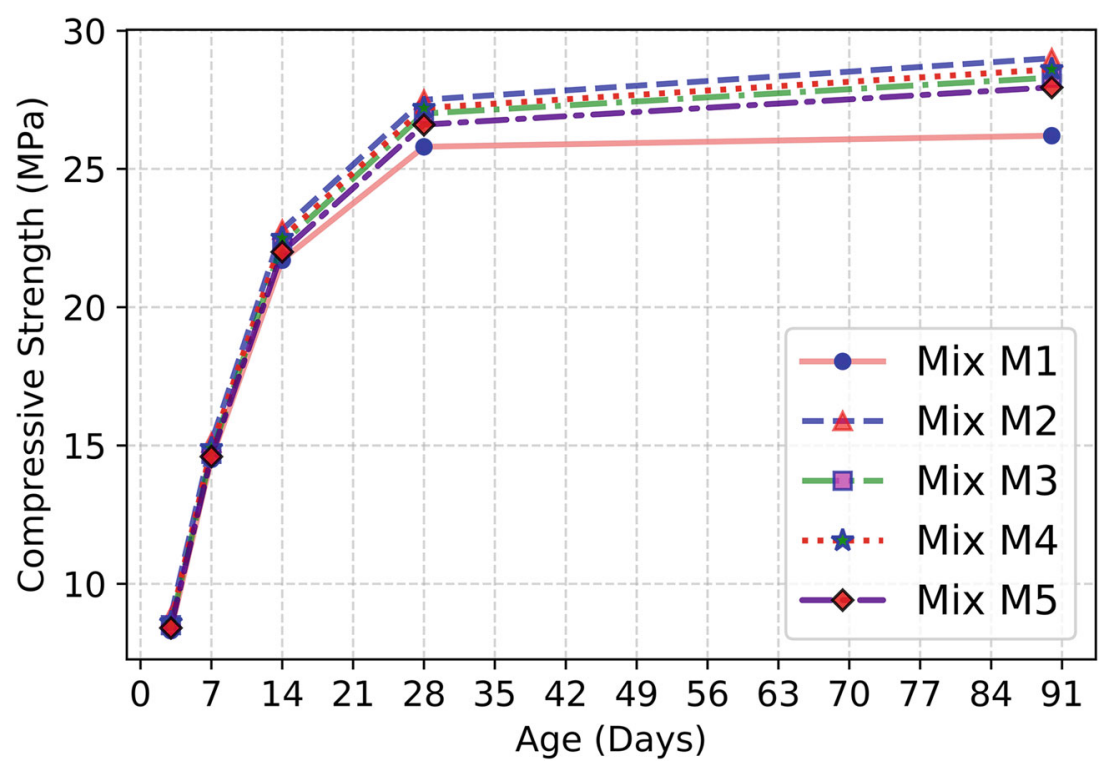

plasma optical emission spectrometry (ICP-OES) using a Agilent Technologies spectrometer. The leachate samples were tested for $\mathrm{pH}$ at time intervals of 6, 24, 54 hours and 4, $9,19,36$ and 64 days. The permissible limits on leachable concentration of chemical contaminants as stipulated by US EPA (2010) [49] was considered for evaluation of risk posed from leachate samples of eco-friendly concrete.

\section{Microstructural characterization of eco-friendly concrete}

The visual examination of internal morphology and microstructure of the hydration products of eco-friendly concrete specimens was carried out by means of Scanning Electron Microscope (SEM) images captured at magnifications of 500X - 4000X.

\section{Results and discussion}

An attempt was made to study the interaction of MSW incinerator bottom ash with manufactured sand as fine aggregate in concrete made with blended coarse aggregates (recycled demolition waste aggregate and crushed granite gravel). The fresh state concrete properties i.e., the slump and Vee-Bee consistency of eco-friendly concrete mixes are presented in Table 5. The slump values of different mixes varied between $74 \mathrm{~mm}$ to $90 \mathrm{~mm}$ indicating a "moist mix" of fair workability. Due to the addition of MSW incinerator bottom ash the viscosity and shear modulus of fresh ecofriendly concrete mixes increased facilitating a lubricant effect along with good cohesion for compactability of concrete. The pore filling effect of MSW incinerator bottom ash rendered negligible bleeding in eco-friendly concrete mixes. The consistency of concrete measured as Vee-Bee degrees

Table 6 Split Tensile and Flexural strengths of Eco-friendly concrete mixes

\begin{tabular}{lllll}
\hline MIX & $\begin{array}{l}\text { Split Tensile } \\
\text { Strength (MPa) }\end{array}$ & $\begin{array}{l}\text { Percent } \\
\text { Increase/Decrease }\end{array}$ & $\begin{array}{l}\text { Flexural } \\
\text { Strength (MPa) }\end{array}$ & $\begin{array}{l}\text { Percent } \\
\text { Increase/Decrease }\end{array}$ \\
\hline M1 & 2.40 & - & 3.63 & - \\
M2 & 2.62 & +9.17 & 4.19 & +15.37 \\
M3 & 2.50 & +4.17 & 4.00 & +10.14 \\
M4 & 2.43 & +1.25 & 3.74 & +2.98 \\
M5 & 2.33 & -2.92 & 3.40 & -6.38 \\
\hline
\end{tabular}

Percent Increase/Decrease in strength is with reference to the control mix - M1 
Table 7 Results of Non Destructive Tests

\begin{tabular}{|c|c|c|c|c|}
\hline \multirow[t]{2}{*}{ MIX } & \multicolumn{2}{|c|}{ Rebound Hammer Test } & \multicolumn{2}{|l|}{ UPV Test } \\
\hline & $\begin{array}{l}\text { Average } \\
\text { Rebound Number }\end{array}$ & Strength $(\mathrm{MPa})$ & $\begin{array}{l}\text { Pulse velocity } \\
(\mathrm{m} / \mathrm{s})\end{array}$ & Time $(\mu \mathrm{s})$ \\
\hline M1 & 36 & 25.75 & 4020 & 36.9 \\
\hline M2 & 39 & 28.5 & 4415 & 33.9 \\
\hline M3 & 37 & 26.5 & 4320 & 34.9 \\
\hline M4 & 38 & 27.35 & 4370 & 35.4 \\
\hline M5 & 37 & 26.25 & 4235 & 36.3 \\
\hline
\end{tabular}

(time in seconds) corresponds to the remoulding effort required to change the concrete mass from one definite shape to another. Concrete mixes with the same consistency can foster different workabilities, due to variations in the size, shape and surface texture of aggregates in the mix.

Average compressive strength obtained from the testing of triplicate cubes were used to plot the strength gain curve of the eco-friendly concrete mixes with age (Figure 3). The magnitude of 3 and 7 days strength of all the mixes varied relatively to each other. Significant variations in the compressive strength development of eco-friendly concrete mixes were observed at 28 and 90 days of testing. The maximum 28 days strength of $27.5 \mathrm{MPa}$ was obtained from cubes of M2 mix, this magnitude later increased to 29 $\mathrm{MPa}$ at 90 days of testing. In contrast, the concrete cubes of control mix (M1) had attained a strength of $25.8 \mathrm{MPa}$ and $26.2 \mathrm{MPa}$ at the age of 28 and 90 days, respectively. With reference to control mix (M1), the strength of ecofriendly concrete mixes M2, M3, M4, \& M5 at 90 days increased by $10.69 \%, 8.02 \%, 9.16 \% \& 6.68 \%$, respectively. With an increase in MSW incinerator bottom ash content from $5 \%$ to $10 \%$ in the M4 and M5 concrete mixes, the strength of concrete relatively reduced owing to the interaction between any potential deleterious substances and the hydration products. In a similar manner, another finding was that with the increase in substitution of recycled demolition waste (RDW) aggregate from $40 \%$ to $60 \%$, the compressive strength relatively reduced in the M3 and M5 concrete mixes. Under certain assumptions, this phenomenon could be due to intense heterogeneity within the concrete matrix and weak interfacial bonding between the cement paste and RDW aggregates. The strength gain in eco-friendly concrete mixes even after 28 days was perhaps attributed by the blending of MSW incinerator bottom ash in the mixes. It is notable that incinerator bottom ash with its chemically active silica and alumina readily reacts with the free lime to form additional insoluble and stable compounds of cementitious value.
The Table 6 below presents the split tensile and flexural strengths of eco-friendly concrete mixes at the age of 28 days. The maximum average tensile strength of $2.62 \mathrm{MPa}$ was observed while testing the cylinders of M2 mix, as against 2.40 MPa strength observed in the case of control mix (M1). The tensile strength of M5 mix (containing $10 \%$ MSW bottom ash and 60\% RDW aggregate) relatively reduced by $2.92 \%$ of strength of control mix, owing to the degradation of paste quality by acute toxic elements of incinerator bottom ash at the interfacial transition zone. The substitution of MSW bottom ash at a dosage of 5\% in eco-friendly concrete mixes M2 and M3 demonstrated significant increase in flexural strength by $15.37 \%$ and $10.14 \%$ as against the reference concrete mix (M1). Likewise, the eco-friendly concrete mixes made with $40 \%$ substitution of RDW aggregates realized an increased flexural strength performance as against the concrete mixes with $60 \%$ RDW aggregates. Variations in the flexural strength of eco-friendly concrete mixes followed a pattern similar to that of the tensile strength behavior. On the whole, better tensile and flexural strength results achieved from M2 mix, in vivid portray it as an optimal mix combination. The optimum blend of natural crushed aggregates and

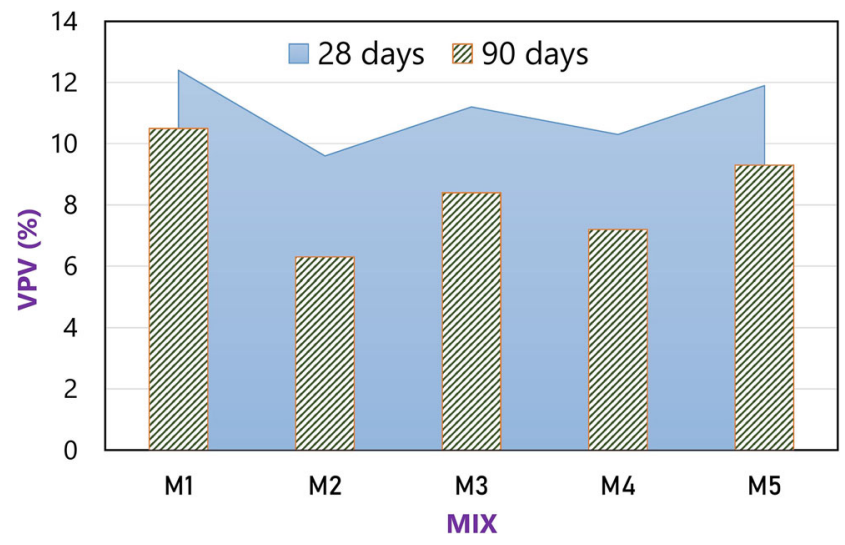

Fig. 4 Volume of Permeable Voids in eco-friendly concrete specimens with age 
Table 8 Toxicity analysis of the expelled leachate from eco-friendly concrete specimens at the age of 64 days

\begin{tabular}{|c|c|c|c|c|c|c|}
\hline \multirow[t]{2}{*}{ Element } & \multirow[t]{2}{*}{$\begin{array}{l}\text { Wavelength } \\
(\mathrm{nm})\end{array}$} & \multicolumn{4}{|c|}{$\begin{array}{l}\text { Concentration of toxic } \\
\text { elements (ppm) }\end{array}$} & \multirow[t]{2}{*}{$\begin{array}{l}\text { Regulated } \\
\text { level (ppm) }\end{array}$} \\
\hline & & M2 & M3 & M4 & M5 & \\
\hline Aluminium & 166.011 & 0.02 & 0.04 & 0.10 & 0.13 & 0.2 \\
\hline \multirow[t]{3}{*}{ Arsenic } & 188.905 & 0.32 & 0.48 & 0.66 & 0.72 & 5.0 \\
\hline & 189.080 & 0.04 & 0.07 & 0.11 & 0.15 & 5.0 \\
\hline & 201.344 & 0.01 & 0.02 & 0.06 & 0.09 & 5.0 \\
\hline \multirow[t]{4}{*}{ Barium } & 223.557 & 1.56 & 1.96 & 3.05 & 3.33 & 100 \\
\hline & 479.903 & 1.22 & 1.54 & 3.26 & 3.65 & 100 \\
\hline & 483.008 & 1.36 & 1.88 & 2.87 & 3.11 & 100 \\
\hline & 604.631 & 0.98 & 1.32 & 2.54 & 2.97 & 100 \\
\hline \multirow[t]{4}{*}{ Boron } & 180.457 & 1.10 & 1.65 & 2.65 & 3.66 & 1.4 \\
\hline & 217.909 & 0.98 & 1.30 & 2.43 & 3.28 & 1.4 \\
\hline & 239.680 & 0.97 & 1.21 & 2.22 & 3.03 & 1.4 \\
\hline & 249.632 & 0.97 & 1.18 & 2.03 & 2.95 & 1.4 \\
\hline \multirow[t]{4}{*}{ Cadmium } & 203.466 & bdl & bdl & bdl & bdl & 1.0 \\
\hline & 234.753 & bdl & bdl & bdl & bdl & 1.0 \\
\hline & 235.862 & bdl & bdl & bdl & bdl & 1.0 \\
\hline & 243.452 & bdl & bdl & bdl & bdl & 1.0 \\
\hline \multirow[t]{4}{*}{ Chromium } & 200.060 & bdl & bdl & 0.21 & 0.35 & 5.0 \\
\hline & 219.658 & bdl & bdl & 0.15 & 0.22 & 5.0 \\
\hline & 319.235 & bdl & bdl & 0.09 & 0.18 & 5.0 \\
\hline & 353.808 & bdl & bdl & 0.05 & 0.11 & 5.0 \\
\hline \multirow[t]{3}{*}{ Cobalt } & 230.305 & bdl & 0.05 & 0.25 & 0.28 & 1.0 \\
\hline & 203.886 & bdl & 0.03 & 0.14 & 0.20 & 1.0 \\
\hline & 225.433 & bdl & 0.03 & 0.06 & 0.11 & 1.0 \\
\hline Copper & 243.100 & bdl & bdl & 0.15 & 0.2 & 1.0 \\
\hline \multirow[t]{2}{*}{ - Ionic form 1} & 210.004 & bdl & bdl & 0.11 & 0.17 & 1.0 \\
\hline & 229.823 & bdl & bdl & 0.08 & 0.16 & 1.0 \\
\hline - Ionic form 2 & 331.675 & 0.14 & 0.19 & 0.21 & 0.22 & 1.0 \\
\hline \multirow[t]{2}{*}{ Gallium } & 276.443 & bdl & bdl & bdl & bdl & 1.0 \\
\hline & 289.658 & bdl & bdl & bdl & bdl & 1.0 \\
\hline \multirow[t]{4}{*}{ Iron } & 236.104 & bdl & 0.04 & 0.10 & 0.12 & 0.3 \\
\hline & 236.883 & bdl & 0.04 & 0.09 & 0.12 & 0.3 \\
\hline & 251.432 & bdl & 0.02 & 0.09 & 0.07 & 0.3 \\
\hline & 260.670 & bdl & 0.02 & 0.06 & 0.07 & 0.3 \\
\hline \multirow[t]{2}{*}{ Lead } & 213.663 & bdl & 0.17 & 0.21 & 0.44 & 5.0 \\
\hline & 254.487 & 0.05 & 0.13 & 0.19 & 0.32 & 5.0 \\
\hline \multirow[t]{2}{*}{ Manganese } & 261.630 & bdl & bdl & bdl & bdl & 0.05 \\
\hline & 267.542 & bdl & bdl & bdl & bdl & 0.05 \\
\hline \multirow[t]{2}{*}{ Nickel } & 215.643 & bdl & bdl & 0.04 & 0.06 & 1.0 \\
\hline & 226.303 & bdl & bdl & 0.03 & 0.05 & 1.0 \\
\hline \multirow[t]{3}{*}{ Silver } & 241.379 & bdl & bdl & bdl & bdl & 5.0 \\
\hline & 252.216 & bdl & bdl & bdl & bdl & 5.0 \\
\hline & 333.458 & bdl & bdl & bdl & bdl & 5.0 \\
\hline \multirow[t]{2}{*}{ Zinc } & 210.220 & 0.03 & 0.07 & 0.13 & 0.24 & 1.5 \\
\hline & 219.457 & 0.01 & 0.06 & 0.13 & 0.21 & 1.5 \\
\hline
\end{tabular}

bdl - below detection limit 
recycled demolition waste aggregates increases the intact bond strength between the binder and the aggregates, and therefore increases both the tensile and flexural strengths. Additionally, when reactive aggregates like the MSW incinerator bottom ash are substituted, its free silica reacts with the excessive calcium hydroxide (one of the cement hydration product) to yield calcium silicate and other by-products which increases the overall strength of the concrete.

The test results of eco-friendly concrete cubes subjected to rebound hammer and ultrasonic pulse velocity measurements at the age of 28 days are presented in Table 7. The concrete of control mix M1 reflects slightly less rebound number than the eco-friendly concrete mixes. The estimated strength values based on average rebound number were slightly equivalent to the corresponding cube compressive strength results of the eco-friendly concrete. The pulse velocity values in the range $4020-4415 \mathrm{~m} / \mathrm{s}$ proclaims the quality of all eco-friendly concrete mixes as "Good" grade as per IS:13311[Part-1]-1992 (2004) [45]. The propagation of pulse velocity through a specimen depends upon factors such as voids percentage, moisture content, density of aggregates, degree of shrinkage cracks, homogeneity and so on. There exists a strong correlation $(\mathrm{R}=0.9)$ between the compressive strength and pulse velocity values.

One of the reasons for premature deterioration of concrete has been an ingress of aggressive agents and moisture through minute pores or permeable voids within concrete. Figure 4 shows the percent volume of permeable voids (VPV) prevailing in the eco-friendly concrete specimens assessed at the age of 28 and 90 days. It was observed that the VPV of M2 mix specimens were less by $2.8 \%$ and $4.2 \%$ at 28 and 90 days, respectively when compared to that of control mix M1. The eco-friendly mix M4 containing 10\% MSW bottom ash had slightly higher percentage of voids compared to M2 mix. This outcome might be due to pop-out of toxic reactions between MSW bottom ash and other hydration compounds, leading to entrapped micro-pores and interconnected voids within the concrete. The bonding defects that exist between the recycled aggregates and other concrete constituents were the reason for increase in the percentage of voids in M3 and M5 mixes. Comparably less percentage of VPV in the optimal M2 mix concrete was perhaps attributed by secondary mineralogical hydrates precipitated around the MSW bottom ash particles that fill micro-pores and lead to both pore-size and grain-size refinements.

The concentration of selected elements in the aqueous leachate generated from eco-friendly concrete specimens containing MSW incinerator bottom ash was determined by inductively coupled plasma optical emission spectrometry (ICP-OES). Table 8 presents the concentration of 15 toxic elements analyzed from the leachate samples of each of the eco-friendly concrete mixes (M2, M3, M4 \& M5). It is well know that under high alkaline conditions, most heavy metals get precipitated. The Figure 5 compares the changes in the $\mathrm{pH}$ of aqueous leachate samples of each eco-friendly concrete mix with age. The $\mathrm{pH}$ of the leachate samples increased parabolically during the initial 10 days and later followed an upward linear trend up to 64 days of leaching time. Leaching of soluble $\mathrm{Ca}(\mathrm{OH})_{2}$ and $\mathrm{CaCO}_{3}$ from eco-friendly concrete facilitates the growth of alkalinity in leachates samples. As Table 8 shows, the concentration of most of the elements analyzed were below the limits or regulated level, except the concentration of Boron which exceeds its corresponding limit in the leachate samples of M3, M4 and M5 mixes. Several catalytic reactions are known to stabilize the heavy metals contributed from incinerator bottom ash; for example, the zinc gets stabilized as calcium
Fig. $5 \mathrm{pH}$ of aqueous leachate samples generated from eco-friendly concrete specimens with age

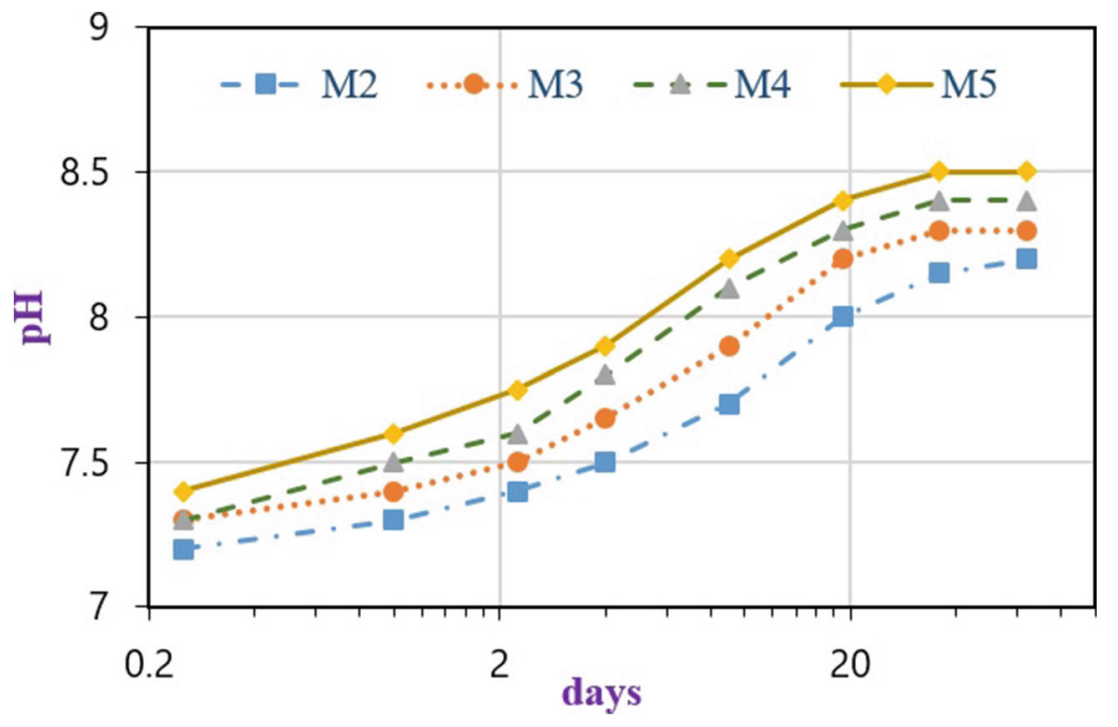



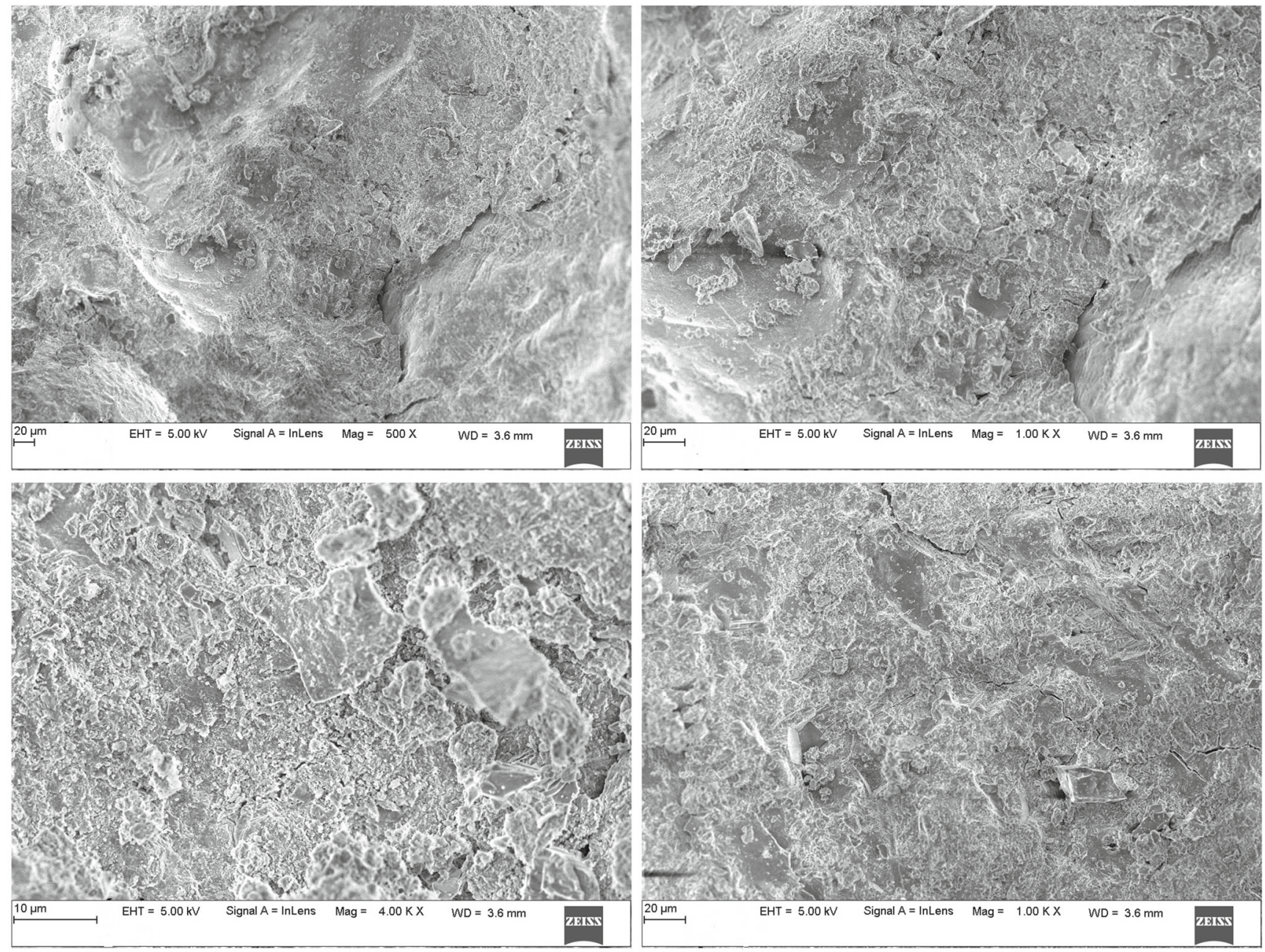

Fig. 6 SEM images depicting inhomogeneity in the microstructure of eco-friendly concrete

zincate $\left[\mathrm{CaZn}_{2}(\mathrm{OH})_{5} .2 \mathrm{H}_{2} \mathrm{O}\right]$, and the oxyanionic chromate $\left[\mathrm{CrO}_{4}^{2-}\right]$ replaces $\mathrm{SO}_{4}^{2-}$ in ettringite (AFt) and monosulfate (AFm) products of hydration [50]. The elemental analysis of leachate sample of M2 eco-friendly concrete mix revealed negligible concentrations of contaminants leaching out from concrete thereby fulfilling the environmental stipulations. The pretreatment of MSW incinerator bottom ash therefore, renders an environmentally stable end-product for usage as substitution material in concrete.

The inhomogeneities in the microstructure of concrete is generally accompanied by the formation of internal micro-cracks which, when subjected to tensile stresses caused by weathering and loading effects during the service life, gradually grow into surface defects [51]. The SEM micrographs presented in Figure 6 reveals that, the partial replacement of MSW incinerator bottom ash with M sand in eco-friendly concrete mixes imparts a non-uniform compact pore structure system with multiphase products primarily of calcium silicate hydrate (C-S-H) and calcium alumino sulphate hydrates. However, micro-cracks that look insignificant, typically less than $10 \mu \mathrm{m}$ were observed at interfacial transition zone (ITZ) between paste matrix and fine aggregates. The heavy metals immobilize through chemical adsorption and multiple isomorphous replacement in hydrated silicate or aluminate phases [52].

\section{Conclusions}

The eco-friendly concrete produced by utilizing MSW incinerator bottom ash and recycled demolition waste aggregates proved to be an excellent alternative to conventional concrete. The increase in compressive strength of eco-friendly concrete even after 28 days, makes it acceptable for all structural applications. The optimal replacement percentage of MSW incinerator bottom ash and recycled demolition waste aggregates was $5 \%$ and $40 \%$, respectively to attain significant strength and durability properties. The percent volume of permeable voids in specimens of eco-friendly concrete mixes were much lower 
compared to control mix concrete. The pretreatment of MSW incinerator bottom ash rendered an environmentally stable end-product for usage as substitution material in concrete. Laboratory tank leaching tests showed that the eco-friendly concrete do not pose any significant environmental hazard. Furthermore, the microstructural analysis revealed dense aggregate paste matrix interfaces with less micro-pores and insignificant micro-cracks due to the incorporation of incinerator bottom ash as a partial replacement to the fine aggregate. The determination of sulphates and chlorides in the eco-friendly concrete could be considered as a future scope of work.

Acknowledgements The authors wish to acknowledge the cooperation rendered by the non-teaching staff of Department of Civil Engineering, SJBIT, Bengaluru and the management of SJBIT, Bengaluru for the necessary infrastructural support for obtaining the experimental data presented in the manuscript.

Funding This research received no external funding.

Availability of Data and Material The datasets generated during and/or analyzed during the current study are available from the authors on reasonable request.

CRediT author statement B. M. Ramesh: Conceptualization, Methodology, Resources; Sujay Raghavendra Naganna: Writing - Original draft, Visualization; B. M. Sreedhara: Writing - Original Draft; Gireesh Mailar: Validation, Data Curation; P. S. Ramesh: Supervision; Rahul Murali Vongole: Investigation, Resources; Yashas Nagraj: Investigation, Resources; Zaher Mundher Yaseen: Writing - Reviewing and Editing.

\section{Declarations}

Conflicts of Interest/Competing Interests The authors confirm that there are no known conflicts of interest associated with this publication and there has been no financial gains for this work that could have influenced its outcome.

\section{References}

1. Proske T, Hainer S, Rezvani M, Graubner CA (2013) Ecofriendly concretes with reduced water and cement contents - Mix design principles and laboratory tests. Cem Concr Res 51:38-46. https://doi.org/10.1016/j.cemconres.2013.04.011

2. Revilla-Cuesta V, Skaf M, Faleschini F, Manso JM, Ortega-López V (2020) Self-compacting concrete manufactured with recycled concrete aggregate: an overview. J Clean Prod 262:121362

3. Xuan D, Zhan B, Poon CS (2016) Development of a new generation of eco-friendly concrete blocks by accelerated mineral carbonation. J Clean Prod 133:1235-1241. https://doi.org/10.1016/j.jclepro.2016.06.062

4. Javali S, Chandrashekar A, Naganna SR, Manu D, Hiremath P, Preethi H, Kumar NV (2017) Eco-concrete for sustainability: utilizing aluminium dross and iron slag as partial replacement materials. Clean Techn Environ Policy 19(9):2291-2304. https://doi.org/10.1007/s10098-017-1419-9
5. Zareei SA, Ameri F, Bahrami N (2018) Microstructure, strength, and durability of eco-friendly concretes containing sugarcane bagasse ash. Constr Build Mater 184:258-268. https://doi.org/10.1016/j.conbuildmat.2018.06.153

6. Naganna SR, Jayakesh K, Anand V (2020) Nano- $\mathrm{TiO}_{2}$ particles: a photocatalytic admixture to amp up the performance efficiency of cementitious composites. Sādhanā, 280. https://doi.org/10.1007/s12046-020-01515-x

7. Tokyay M (2016) Cement and concrete mineral admixtures. CRC Press, Boca Raton

8. ISWA GS (2013) International solid waste association report. Tech. rep., ISWA, Vienna, Austria, https://www.iswa.org/ fileadmin/galleries/Publications/ISWA_Reports/ISWA_Report_ 2013.pdf

9. Assi A, Bilo F, Zanoletti A, Ponti J, Valsesia A, La Spina R, Zacco A, Bontempi E (2020) Zero-waste approach in municipal solid waste incineration: Reuse of bottom ash to stabilize fly ash. J Clean Prod 245:118779

10. Giro-Paloma J, Mañosa J, Maldonado-Alameda A, Quina MJ, Chimenos J (2019) Rapid sintering of weathered municipal solid waste incinerator bottom ash and rice husk for lightweight aggregate manufacturing and product properties. J Clean Prod 232:713-721

11. Ray S, Daudi L, Yadav H, Ransinchung G (2020) Utilization of jarosite waste for the development of sustainable concrete by reducing the cement content. J Clean Prod 272:122546

12. Joseph AM, Snellings R, Van den Heede P, Matthys S, De Belie $\mathrm{N}$ (2018) The use of municipal solid waste incineration ash in various building materials: A Belgian point of view. Materials 11(1):141. https://doi.org/10.3390/ma11010141

13. Lam CH, Ip AW, Barford JP, McKay G (2010) Use of incineration MSW ash: a review. Sustainability 2(7):1943-1968. https://doi.org/10.3390/su2071943

14. Silva R, De Brito J, Lynn C, Dhir R (2017) Use of municipal solid waste incineration bottom ashes in alkali-activated materials, ceramics and granular applications: a review. Waste Manag 68:207-220. https://doi.org/10.1016/j.wasman.2017.06.043

15. Akhtar A, Sarmah AK (2018) Construction and demolition waste generation and properties of recycled aggregate concrete: a global perspective. J Clean Prod 186:262-281. https://doi.org/10.1016/j.jclepro.2018.03.085

16. Wang XY (2020) Design of low cost and low $\mathrm{CO}_{2}$ air-entrained fly ash blended concrete considering carbonation and frost durability. J Clean Prod 272:122675

17. Banerjee $C$ (2015) C\&d Waste Processing in India - Delhi shows the way. New Building Material \& Construction World 12:20-25

18. Al Muhit BA, An J, Nam BH (2015) Recycling of Municipal Solid Waste Incineration (MSWI) Ash as Aggregate Replacement in Concrete. In: Iskander M, Suleiman MT, Anderson B, Laefer DF (eds) American Society of Civil Engineers, vol 2015, 2797-2806. San Antonio, Texas. https://doi.org/10.1061/9780784479087.261

19. Pavlík Z, Keppert M, Pavlíková M, Volfová P et al (2011) Application of MSWI bottom ash as alternative aggregate in cement mortar. WIT Trans Ecol Environ 148:335-342. https://doi.org/10.2495/RAV110311

20. Siddique R (2010) Utilization of municipal solid waste (MSW) ash in cement and mortar. Resour Conserv Recycl 54(12):1037-1047. https://doi.org/10.1016/j.resconrec.2010.05. 002

21. Ren P, Li B, Yu JG, Ling TC (2020) Utilization of recycled concrete fines and powders to produce alkali-activated slag concrete blocks. J Clean Prod 267:122115

22. Wongsa A, Boonserm K, Waisurasingha C, Sata V, Chindaprasirt $\mathrm{P}$ (2017) Use of municipal solid waste incinerator (mswi) bottom 
ash in high calcium fly ash geopolymer matrix. J Clean Prod 148:49-59

23. Ahmed SFU (2013) Properties of concrete containing construction and demolition wastes and fly ash. J Mater Civ Eng 25(12):18641870, https://doi.org/10.1061/(ASCE)MT.1943-5533.0000763

24. Mailar G, Sujay Raghavendra N, Hiremath P, Sreedhara B, Manu D (2017) Sustainable utilization of discarded foundry sand and crushed brick masonry aggregate in the production of lightweight concrete. Eng Struct Tech 9(1):52-61. https://doi.org/10.3846/2029882X.2017.1279987

25. Zhang T, Zhao Z (2014) Optimal use of MSWI bottom ash in concrete. Int $\mathbf{J}$ Concr Struct Mater 8(2):173-182. https://doi.org/10.1007/s40069-014-0073-4

26. Lynn CJ, Dhir OBERK, Ghataora GS (2016) Municipal incinerated bottom ash characteristics and potential for use as aggregate in concrete. Constr Build Mater 127:504-517. https://doi.org/10.1016/j.conbuildmat.2016.09.132

27. Saikia N, Mertens G, Van Balen K, Elsen J, Van Gerven T, Vandecasteele C (2015) Pre-treatment of municipal solid waste incineration (MSWI) bottom ash for utilisation in cement mortar. Constr Build Mater 96:76-85. https://doi.org/10.1016/j.conbuildmat.2015.07.185

28. Zhu X, Yuan Y, Li L, Liu D, Ling J (2016) Utilize nanoscale metrology techniques to investigate mechanical, structural, and chemical heterogeneity of mixtures contained incineration bottom ash aggregate. Constr Build Mater 127:627-642. https://doi.org/10.1016/j.conbuildmat.2016.10.033

29. Liu Y, Sidhu KS, Chen Z, Yang EH (2018) Alkalitreated incineration bottom ash as supplementary cementitious materials. Constr Build Mater 179:371-378. https://doi.org/10.1016/j.conbuildmat.2018.05.231

30. Li X, Liu Z, Lv Y, Cai L, Jiang D, Jiang W, Jian S (2018) Utilization of municipal solid waste incineration bottom ash in autoclaved aerated concrete. Constr Build Mater 178:175-182. https://doi.org/10.1016/j.conbuildmat.2018.05.147

31. Guo H, Shi C, Guan X, Zhu J, Ding Y, Ling TC, Zhang H, Wang Y (2018) Durability of recycled aggregate concrete-A review. Cem Concr Compos 89:251-259. https://doi.org/10.1016/j.cemconcomp.2018.03.008

32. Jain N, Garg M, Minocha A (2015) Green concrete from sustainable recycled coarse aggregates: Mechanical and durability properties. J Waste Manag 2015:281043. https://doi.org/10.1155/2015/281043

33. Yehia S, Helal K, Abusharkh A, Zaher A, Istaitiyeh $\mathrm{H}$ (2015) Strength and durability evaluation of recycled aggregate concrete. Int J Concr Struct Mater 9(2):219-239. https://doi.org/10.1007/s40069-015-0100-0

34. Kuo WT, Liu CC, Su DS (2013) Use of washed municipal solid waste incinerator bottom ash in pervious concrete. Cem Concr Compos 37:328-335

35. Wiles CC (1996) Municipal solid waste combustion ash: State-of-the-knowledge. J Hazard Mater 47(1-3):325-344. https://doi.org/10.1016/0304-3894(95)00120-4

36. Clavier KA, Watts B, Liu Y, Ferraro CC, Townsend TG (2019) Risk and performance assessmentof cement made using municipal solid waste incinerator bottom ash as a cement kiln feed. Resour Conserv Recycl 146:270-279

37. Robu I, Mazilu C, Deju R (2016) Aspects concerning the use of recycled concrete aggregates. In: IOP Conference Series: Materials Science and Engineering, vol:161(1), p 012072, https:// iopscience.iop.org/article/10.1088/1757-899X/161/1/012072/pdf

38. IS:12269-2013 (2013) Ordinary Portland Cement, 53 Grade Specification. Bureau of Indian Standards, New Delhi, 1st edn

39. IS:383-1970 (2002) Specification for coarse and fine aggregates from natural sources for concrete. Bureau of Indian Standards, New Delhi, 2nd edn

40. IS:10500-2012 (2012) Indian Standard Drinking water - Specification. Bureau of Indian Standards, New Delhi, 2nd edn

41. IS:10262-2009 (2009) Guidelines for concrete mix design proportioning. Bureau of Indian Standards, New Delhi, 1st edn

42. IS:1199-1959 (1991) Methods of sampling and analysis of concrete. Bureau of Indian Standards, New Delhi, eleventh edn

43. IS:516-1959 (2006) Method of Tests for Strength of Concrete. Bureau of Indian Standards, New Delhi, eighteenth edn

44. IS:5816-1999 (2004) Splitting Tensile Strength of Concrete Method of Test. Bureau of Indian Standards, New Delhi, 1st edn

45. IS:13311[Part-1]-1992 (2004) Method of Non-destructive testing of concrete - Methods of test, Part 1: Ultrasonic Pulse Velocity. Bureau of Indian Standards, New Delhi, 1st edn

46. IS:13311[Part-2]-1992 (2004) Method of Non-destructive testing of concrete - Methods of test, Part 2: Rebound Hammer. Bureau of Indian Standards, New Delhi, 1st edn

47. ASTM:C642-06 (2006) Standard Test Method for Density, Absorption, and Voids in Hardened Concrete. ASTM International, PA, United States

48. EA NEN 7375:2004 (2005) Leaching characteristics of solid earthy and stony building and waste materials. Leaching tests: Determination of leaching of inorganic components from building and monolithic waste materials with the diffusion test. Nederlands Normalisatie-instituut, Delft, Netherlands

49. US EPA (2010) The EPA TCLP: Toxicity Characteristic Leaching Procedure and Characteristic Wastes. Environmental Services Division, US EPA, New Jersey, http://www.ehso.com/TCLP.htm

50. Yang Z, Ru J, Liu L, Wang X, Zhang Z (2018) Longterm leaching behaviours of cement composites prepared by hazardous wastes. RSC Advances 8:27602-27609. https://doi.org/10.1039/C8RA02773K

51. Mehta PK (2005) Fundamental principles for radical enhancement of durability of concrete. In: Proc. Second international symposium on concrete technology for sustainable development. Hyderabad, Indi, pp 83-93

52. Fan C, Wang B, Zhang T (2018) Review on cement stabilization/solidification of municipal solid waste incineration fly ash. Adv Mater Sci Eng 2018:5120649. https://doi.org/10.1155/2018/5120649

Publisher's Note Springer Nature remains neutral with regard to jurisdictional claims in published maps and institutional affiliations. 